\title{
Designing and using an online survey as a tool for teaching pharmacy students about COVID-19
}

\author{
N.A. Sabry*, A. Kamel, S.A Farid \\ Faculty of Pharmacy, Cairo University, Egypt
}

\author{
Keywords \\ COVID-19 \\ Survey \\ Google Form \\ Egypt
}

*Corresponding author:
nirmeen.sabry@pharma.cu.edu.eq

\begin{abstract}
Summary: Final year pharmacy students were asked to prepare and post an online questionnaire about COVID-19 to evaluate the knowledge, attitude and practice of the Egyptian people in relation to the pandemic. Each student, using Google Forms, distributed the questionnaire. By giving a unique code to every student, the course team were able to track the activities and responses received to each questionnaire. All students were given one week to gather as many responses as possible. Responses were then filtered for any duplications by the course team. Each student was given the responses connected to their own code to work on and analyse. Finally, every student was asked to present their data as a PowerPoint presentation and comment on their results.
\end{abstract}

\section{Background and Context}

The COVID-19 pandemic, caused by severe acute respiratory syndrome coronavirus 2 (COVID-19), continues to spread globally (World Health Organisation, 2020). The first COVID-19 case in Egypt was announced on 15th February 2020 (Al-Tawy, 2020). To slow down the spread of the virus, the Egyptian government imposed strict physical distancing (i.e. lockdown) measures. On 18th March 2020, the Egyptian government locked down all the schools and universities in Egypt (Ahram Online, 2020). Since that date, all academic activities have had to be conducted virtually. Final-year pharmacy students at Cairo University were completing a module on management of respiratory disorders. One of the methods of evaluating the students' knowledge in this module involved two different quizzes during their term. Because of the lockdown, Cairo University requested each course coordinator to replace all written exams with other methods of evaluation which did not require in-person interactions. The course coordinators thought of filling two needs with one deed, introducing the current topic of COVID-19 to the course, and establishing a virtual method for student evaluation.

\section{Educational Description}

At Cairo University, final-year students were requested to perform two quizzes during the term as part of their assessment. The final-year pharmacy students at Cairo University cohort 2020 was composed of 220 students. As an alternative strategy, the cohort was divided into groups of 25 students, with each group headed by one teaching assistant. Students in each group were asked to draft a questionnaire to be directed to the general Egyptian population asking them about their knowledge, attitude and practice in relation to the COVID-19 pandemic. Students had weekly online meetings with their teaching assistants and were instructed about the methodology of questionnaire development and were provided with a list of references and sources to be used for their task completion. After the ten groups drafted their individual questionnaires, the course coordinator developed a single questionnaire covering the most common and important questions from the students' versions. The questionnaire was then converted to an online version using Google Forms. Each student was requested to share the questionnaire with their social circle using social media platforms. Students were informed that this would be the 
method of assessment instead of the quizzes. To minimise duplications, cheating or fabrications, each student was given a unique code linked to the link they were distributing. Also, to get reliable results, responders were requested to provide their phone numbers for random checking. Each student was encouraged to get a minimum of 100 responses. Students were given seven days to achieve this first step of the assessment. After the seven days, all links were deactivated, and the teaching assistants started to filter the response to delete any duplications based on the provided phone numbers, and also started to delete illogical responses.

Each group of responses were sent to each student based on their own unique codes, for the second step in the evaluation. Each student was requested to analyse the responses they were sent, and deliver a mini-manuscript based on the outcomes they had. The students were provided with an orientation about data analysis and writing manuscripts. After developing the mini report, each student was requested to prepare a short PowerPoint presentation summarising their work and their interpretation of the results. On a departmental level, the students' activity managed to receive 26,000 responses and were used to develop a mega-manuscript about the knowledge, attitude and practice of the Egyptian people in relation to COVID-19. The manuscript is currently in review, and it was mentioned within the manuscript that this work was part of final-year students' evaluation.

Students were asked to reflect on this activity. The majority of the students gave positive feedback about their experiences, especially that they felt it gave them access to both COVID-19 as a disease and allowed them to carry out data analysis for a questionnaire-based study to provide data interpretation and discussion.

\section{Outcomes and Recommendations}

An online descriptive survey was designed and disseminated by final-year pharmacy students via social media platforms. The survey consisted of 32 questions addressing respondent's demographics, knowledge, practice, and attitude towards the COVID-19 pandemic. Approximately 26,000 responses were received, and a total of 220 student reports and presentations about COVID-19 were delivered by the students. A final manuscript is ready for publication.

There are a number of limitations to this strategy, such as some faculty members struggling with novel technology, students struggling with poor internet connections, and some difficulty in reviewing images and files. These challenges, however, can be overcome through an investment of time and effort by staff providers to become more familiar with these techniques.

While there are many challenges to student life during the global COVID-19 pandemic, it has also been a wonderful opportunity to see the importance of field work and the need to better use existing technologies. During this rapidly evolving crisis, a great deal of flexibility will be required from both learners and educators, and many learning methods that are not well-studied may need to be used.

These innovative solutions, which involve using technologies, may help to bridge the educational gap for pharmacy students during this unprecedented circumstance.

\section{References}

Ahram Online. (2020). Egypt closes schools and universities for two weeks over coronavirus concerns. Available at: http://english. ahram.org.eg/NewsContent/1/0/365268/Egypt/0/Egypt-closesschools-and-universities-for-two-week.aspx

Al-Tawy, A. (2020). Egypt detects first coronavirus case in Egyptian national. Available at: http://english.ahram.org.eg/NewsContent/1/ 64/364738/Egypt/Politics-/Egypt-detects-first-Egyptian-coronaviruscase.aspx

World Health Organisation. (2020). Coronavirus disease (COVID-19): Situation Report - 156. Available at: https://www.who.int/docs/ default-source/coronaviruse/situation-reports/20200624-covid-19sitrep-156.pdf?sfvrsn=af42e480 2 